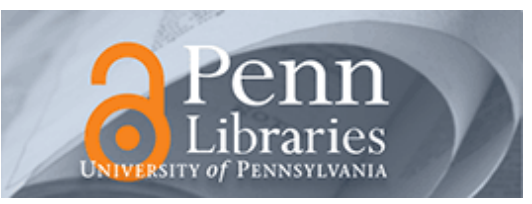

University of Pennsylvania ScholarlyCommons

December 2002

\title{
Legalized Abortion and the Homicide of Young Children: An Empirical Investigation
}

\author{
Susan B. Sorenson \\ University of Pennsylvania, sorenson@sp2.upenn.edu \\ Douglas J. Wiebe \\ University of California \\ Richard A. Berk \\ University of Pennsylvania, berkr@sas.upenn.edu
}

Follow this and additional works at: https://repository.upenn.edu/spp_papers

\section{Recommended Citation}

Sorenson, S. B., Wiebe, D. J., \& Berk, R. A. (2002). Legalized Abortion and the Homicide of Young Children: An Empirical Investigation. Retrieved from https://repository.upenn.edu/spp_papers/72

Postprint version. Published in Analyses of Social Issues and Public Policy, Volume 2, Issue 1, December 2002, pages 239-256.

Publisher URL: http://dx.doi.org/10.1111/j.1530-2415.2002.00040.x

NOTE: At the time of publication, authors Susan B. Sorenson and Richard A. Berk were affiliated with the University of California. Currently (August 2007), she is a faculty member in the School of Social Policy and Practice, and he is a faculty member in the Department of Criminology at the University of Pennsylvania.

This paper is posted at ScholarlyCommons. https://repository.upenn.edu/spp_papers/72

For more information, please contact repository@pobox.upenn.edu. 


\title{
Legalized Abortion and the Homicide of Young Children: An Empirical Investigation
}

\begin{abstract}
Recent research has drawn a link, sometimes a causal link, between the legalization of abortion in the late 1960 s and early 1970s and the precipitous decline in crime in the 1990s. Abortion is posited to have reduced the number of potential victims and potential perpetrators, and the potential effect is examined when these individuals would be reaching their high-crime years. We examined a more proximal potential association between legalized abortion and homicide, specifically, the homicide of young children. Assuming that abortions occurred when the family had insufficient resources for the birth, one could hypothesize that children would have been at higher risk of homicide if born into these circumstances. We examined 1960-1998 U.S. mortality data for children under 5 years of age using an interrupted time series design. The legalization of abortion was not associated with a sudden change in child homicide trends. It was, however, associated with a steady decrease in the homicides of toddlers (i.e., 1- to 4-year-olds) in subsequent years. Although in the predicted direction, the decrease in homicides of children under 1 year of age was not statistically significant. Competing explanations that could be examined in the data (e.g., changes in mortality classification) do not account for the findings.
\end{abstract}

\section{Keywords}

legalized abortion, young homicide

\section{Comments}

Postprint version. Published in Analyses of Social Issues and Public Policy, Volume 2, Issue 1, December 2002, pages 239-256.

Publisher URL: http://dx.doi.org/10.1111/j.1530-2415.2002.00040.x

NOTE: At the time of publication, authors Susan B. Sorenson and Richard A. Berk were affiliated with the University of California. Currently (August 2007), she is a faculty member in the School of Social Policy and Practice, and he is a faculty member in the Department of Criminology at the University of Pennsylvania. 
Running head: LEGALIZED ABORTION AND CHILD HOMICIDE

\author{
Legalized Abortion and the Homicide of Young Children: \\ An Empirical Investigation
}

Susan B. Sorenson and Douglas J. Wiebe

School of Public Health

Richard A. Berk

Department of Statistics

University of California, Los Angeles

Words in abstract: 204

Words in text: $\quad 4,389$

Number of tables: $\quad 2$

Number of figures: $\quad 6$

Analyses of Social Issues and Public Policy, 2002, 2, 239-256.

Please access the journal's website for the published version of the paper. 


\begin{abstract}
Recent research has drawn a link, sometimes a causal link, between the legalization of abortion in the late 1960s and early 1970s and the precipitous decline in crime in the 1990s. Abortion is posited to have reduced the number of potential victims and potential perpetrators, and the potential effect is examined when these individuals would be reaching their high-crime years. We examined a more proximal potential association between legalized abortion and homicide, specifically, the homicide of young children. Assuming that abortions occurred when the family had insufficient resources for the birth, one could hypothesize that children would have been at higher risk of homicide if born into these circumstances. We examined 1960-1998 U.S. mortality data for children under 5 years of age using an interrupted time series design. The legalization of abortion was not associated with a sudden change in child homicide trends. It was, however, associated with a steady decrease in the homicides of toddlers (i.e., 1- to 4-year olds) in subsequent years. Although in the predicted direction, the decrease in homicides of children under one year of age was not statistically significant. Competing explanations that could be examined in the data (i.e., changes in mortality classification) do not account for the findings.
\end{abstract}


Legalized Abortion and the Homicide of Young Children:

An Empirical Investigation

Nearly 30 years ago, abortion was legalized in the United States with the Supreme Court decision of Roe v. Wade. Before January 22, 1973, only five states allowed abortion to be performed legally and then only under certain circumstances (e.g., to prevent death, severe impairment, fetal deformity, or in the case of rape or incest) (Merz, Jackson, \& Klerman, 1995). In 1973, approximately 615,000 abortions were performed in the United States (see Figure 1). Between 1973 and 1980, the number of abortions performed increased steadily by about 85,000 abortions annually. Throughout the 1980s and 1990s approximately 1.6 million abortions were performed each year. Both the number of pregnancies and the number of abortions have declined throughout the 1990s. In 1997, the most recent year for which U.S. data are reported, about $22 \%$ of pregnancies were terminated resulting in 1.2 million abortions (Koonin, Strauss, Chrisman, \& Parker, 2000). There have been numerous attempts to alter Roe v. Wade (for a review of U.S. abortion policy since 1973, see Wilcox, Robbennolt, \& O’Keeffe, 1998), and abortion remains a controversial topic in the U.S. (e.g., Russo \& Denious, 1998).

Insert Figure 1 about here

Homicide, a substantial public health problem in the United States, has dropped precipitously since its peak in the early 1990s (e.g., Fox \& Zawitz, 2000). The reasons for the decline are far from clear. Despite broad speculation and numerous claims of credit (e.g., the stabilization of crack cocaine markets, increased incarceration, changes in law enforcement 
policies, a healthy economy), we do not know why crimes, including homicide, have decreased so dramatically.

Recent research by Donohue and Levitt (2001) examined a possible connection between legalized abortion and crime, including homicide. Their work, an econometric analysis using mostly law enforcement data, was vilified by persons and groups on both ends of the political spectrum, mostly, it seems for the moral and ethical implications of the question itself as well as for their statistical methods and the implications of some of their findings. The authors of two subsequent working papers used generally similar methods as Donohue and Leavitt but came to different conclusions - one found little evidence for a causal link (Joyce, 2001), whereas the other concluded that legalized abortion increases homicide (Lott \& Whitley, 2001). (See Berk, Sorenson, Wiebe, \& Upchurch [under review] for a critique of the studies.) Given the importance of the two issues to U.S. society, the question itself deserves further investigation using other methods. While the distal effects of legalized abortion on homicide will continue to be debated, we chose to investigate the potential of a more immediate effect.

The first link, to our knowledge, between legalized abortion and homicide in the published literature was made nearly a generation ago (Robertson, 1981). The researcher, comparing mortality data from 1971-1972 with those from 1974-1975, found with the data available at the time no association between legalized abortion and infant homicide, but did find an association between legalized abortion and non-vehicle accidental deaths. Two earlier studies, which examined overall mortality trends in the very young, found a negligible association between the legalization of abortion and fetal and infant mortality trends (Quick, 1978) and that an observed association between legalized abortion and overall infant mortality could not be distinguished from the ongoing trend of reduced infant mortality (Bauman \& 
Anderson, 1980). A letter about neonatal homicide following the legalization of abortion was published more than a decade after these three studies (Lester, 1992). To our knowledge, no published study, aside from the 1981 investigation, has empirically examined whether an association exists between legalized abortion and infant homicide and none have investigated whether an association exists with the homicides of 1- to 4-year olds.

We hypothesize that legalized abortion was associated with a subsequent reduction in the homicide of infants and toddlers. Eighty percent of fatal child abuse and neglect occurs among children less than five years old (e.g., McClain, Sacks, Froehlke, \& Ewigman, 1993). A young child is more likely to be a homicide victim if the mother is unmarried, a teenager, or has not graduated from high school (Winpisinger, Hopkins, Indian, \& Hostetler, 1991). Infants are at particular risk if the mother is young, has little education, and a previous child (Overpeck, Brenner, Trumble, Trifiletti, \& Berendes, 1998). Although infants are at substantially higher risk of homicide than toddlers (e.g., Murphy, 2000), the child's caretaker is the most common assailant for both age groups (e.g., Jason, Gilliland, \& Tyler, 1983). The caretaker is most likely to be the child’s mother, father, or the mother’s paramour (Jason et al., 1983), in other words, someone who would have likely participated in the decision as to whether to maintain the pregnancy.

It is not possible from the data we analyze in this paper to make any grounded statements about assailant motivation in the homicides of young children. We make no claim that premeditation figures significantly in the vast majority of homicides of infants and toddlers, particularly those at the hands of caretakers. Indeed, such homicides may not be intentional in the usual sense of the word (e.g., Christoffel, 1984). Parental frustration coupled with a lack of understanding of child development along with the physiological vulnerability of young children, 
especially infants, can result in a fatality. For example, a parent can shake an 8-year old child with no long-term physiological consequences, but the same behavior with an 8-week old is likely to result in severe brain injury and possibly death.

Research on abortion seeking and motivations for abortion was typically based on small convenience samples in the 1970s (e.g., Bracken, Hachamovitch, \& Grossman, 1974; Ford, Castelnuovo-Tedscim \& Long, 1972; Friedman, Greenspan, \& Mittleman, 1974; Rosen \& Martindale, 1978). The research evolved to focus on the decision-making process of the woman (e.g., Blum \& Resnick, 1982; Faria, Barrett, \& Goodman, 1985; Friedlander, Kaul, \& Stimel, 1984; Ortiz \& Vazquez Nuttal, 1987; Smetana, 1981; Stevans, Register, \& Sessions, 1992) and who she consulted (e.g., Luscutoff \& Elms, 1975; Finken \& Jacods, 1996). Recent investigations have examined how health information (e.g., HIV status, fetal anomalies) available through technological advances since Roe v. Wade affects a woman's decision to maintain or terminate a pregnancy (e.g., Johnstone, Brettle, MacCallum, Mok, Peutherer, \& Burns, 1990; Schechtman, Gray, Baty, \& Rothman, 2002).

The decision to have an abortion is typically based on multiple reasons (Torres \& Forrest, 1988). The Alan Guttmacher Institute’s (AGI) nationwide surveys of U.S. abortion providers produce the most comprehensive information about U.S. women seeking abortions. Data collected by AGI in 1987 (Torres \& Forrest, 1988) indicate that women seeking abortion identified the most important reason for seeking an abortion to be that she can't afford a baby now (21\%), is not ready for the responsibility of a child (21\%), is concerned about how having a baby could change her life (16\%), or has problems in her relationship or does not want to be a single parent (12\%). The next two most common single reasons - is too young or not mature enough to have a child (11\%) and has all grown-up children or all the children she wants (8\%) - 
reflect the fact that women seeking abortions are not a monolithic group. Ethnicity and race were not factors in the decision to seek an abortion when age, marital status, employment status, and parental status were taken into consideration. (For a reanalysis of these data with a focus on age, marital status, and child-bearing status, please see Russo, Horn, \& Schwartz, 1992.) These findings from the U.S. are documented elsewhere as well, for example, in Sweden where financial concerns, worries about the relationship, and bad timing of the pregnancy were the most common reasons for seeking an abortion (Larsson, Aneblom, Odlind, \& Tyden, 2002). Moreover, in a U.S. study of single, young Black women, most of who were on welfare and previously pregnant, the authors conclude that the decision to abort depends largely upon circumstances surrounding specific pregnancies rather than characteristics of the mother (Bracken, Klerman, \& Bracken, 1978). Therefore, the real and perceived personal and household resources available to provide care for a child are important considerations in whether a woman has an abortion. Abortion may serve as a marker for parental perception of ability to provide and care for a child at that time.

But, in some sense, motivations affecting abortion decisions are, for this paper, beside the point. Ventura and colleagues (Ventura, Mosher, Curtin, Abma, \& Henshaw, 2000) emphasize the obvious when they observe that the availability of means to either prevent or terminate a pregnancy matter. It is clear that with Roe v. Wade an important means of fertility control became far more accessible. And, unless women's motivations to end pregnancy also changed abruptly in that very same year, one can consider the possible short-term effects of Roe v. Wade without worrying a great deal about the underlying motivations of individual women.

Legalized abortion might have an effect on the homicides of both infants and toddlers. One could logically assert that the homicides of infants might be reduced because they would be 
more likely to be born into a household in which they are wanted and in which resources are perceived to be adequate for their care. The homicide of toddlers might be reduced, in addition, because they are the beneficiaries of resources (emotional, financial, etc.) that otherwise would have gone to a newborn. Others might posit that the legalization of abortion would be associated with an increase in the homicides of young children because the general disregard for life represented by abortion would extend to children who have already been born. The present investigation assesses the trends in the homicide of infants and toddlers in association with legalized abortion; the data cannot, however, shed much light on associated underlying mechanisms.

\section{Methods}

\section{$\underline{\text { Study Design }}$}

We used an interrupted time series design with the annual number of homicides of young children (newborns to 4-year olds) in the U.S to assess whether the homicides of young children decreased after the 1973 Supreme Court decision in Roe v. Wade. The Roe v. Wade decision constituted the intervention (i.e., the interruption in the time series). Given that the risk of homicide varies for young children (it is higher for those less than one year of age than for 1- to 4-year olds), we examined the effect of the intervention on these two age groups separately. For ease in describing these groups, we refer to those less than one year of age as infants and to the 1- to 4-year olds as toddlers.

\section{$\underline{\text { Data and Data Sources }}$}

The number of children under age five who died of homicide each year from 1960 through 1998 was obtained from the National Center for Health Statistics (NCHS) (National Center for Health Statistics, 1960-1998). The study population consisted of all deaths of children 
under age five that were classified as homicide by the edition of the International Classification of Diseases (ICD) in use at the time of the death (E964 and E980-985 in the ICD-7, used through 1967; E960-969 in the ICD-8 and ICD-9, used from 1968-1978 and from 1979 on, respectively) (International Classification of Diseases, 1955, 1969, 1977). Two annual time series were constructed for this period, one for infants (less than one year old) and another for toddlers (1- to 4-year olds). Each data value entered in the time series was the number of homicides occurring in the relevant age group each year.

Two changes in the classification system may have affected the number of deaths that were classified as homicides (see Table 1). In 1968, the ICD-8 introduced a cause of death classification labeled “injuries undetermined whether accidentally or purposely inflicted.” The "undetermined” classification was continued in subsequent revisions of the ICD. The coding change may have affected how other deaths, in this case, homicides, were classified. If the category of undetermined was available before 1968, some unknown proportion of the deaths that occurred before 1968 that were classified as homicide might have been classified as undetermined. $^{\text {a }}$ Likewise, the sudden infant death syndrome (SIDS) category was introduced in the 9th revision of the ICD in 1979. To take into account the possibility that, independent of the abortion ruling, a change in the coding schema may have affected the number of deaths classified as homicides, we examined two additional intervention (i.e., interruption) variables - for both age groups, the 1968 introduction of "undetermined" to the classification system and, for the infants, the 1979 introduction of SIDS.

a The category of undetermined is used more often for the deaths of those under age five than other age groups (Sorenson, Shen, \& Kraus, 1997a). Moreover, the proportion of infant and toddler deaths in one large state that were considered undetermined range from a high of $4.7 \%$ in 1972 to a low of $1.2 \%$ in 1981 (Sorenson, Shen, \& Kraus, 1997b). Nearly half of these deaths are very similar to homicides. 


\section{$\underline{\text { Statistical Analysis }}$}

Consistent with the interrupted time series design, we estimated transfer function models to capture the possible role of abortion legalization (Box, Jenkins, \& Reinsel, 1994). We explored two kinds of associations, one in which the average number of homicides declined and one in which the rate of change in the number of homicides declined. Using standard terminology, we refer to these as a change in level and a change in slope, respectively. The transfer functions were initially specified so that any associations with homicide would be found within a year of legalization for infants and within two years for toddlers. We also experimented with delayed effects, as described below. This was done because, although abortion was legal immediately with the U.S. Supreme Court decision, services were not necessarily in place and running immediately. In the end, all of the results we report derive from transfer function models that passed all of the customary diagnostic procedures. In addition to one or more interventions, both time series required a first difference to achieve stationarity and either an autoregressive or moving average parameter at a lag of 1 year to produce white noise residuals. Because we hypothesized that the homicide of young children decreased after the legalization of abortion, one-sided p-values were used in tests of statistical significance. 


\section{Results}

$\underline{\text { Infants }}$

Figure 2 shows the number of infants who died of homicide from 1960 through 1998. It is readily apparent that there are dramatic changes in level with the number of homicides ranging from a low of about 150 to a high of nearly 400. Is there any evidence for a drop in 1973 ?

\section{Insert Figure 2 about here}

The top panel of Table 2 shows the parameter estimates to address that question. The largest association between the number of homicides and any intervention is found for the introduction of the "undetermined" classification in 1968. The average number of homicides dropped by a little over $72(p=.025)$, a reduction of about one third. Note that the reduction reflects a measurement artifact, not a real drop in the number of homicides. The other measurement artifact, the introduction of the SIDS classification in 1979, had virtually no association with the number of homicides; the counterintuitive positive coefficient of 8.7 is likely a chance outcome $(\mathrm{p}=.60)$. Finally, while there is an average reduction of 26 homicides per year after the legalization of abortion, and while that reduction is large enough to be of practical significance, we cannot reject the null hypothesis of no association ( $p=.38$, one-tailed test). 
Figure 3, a plot of the homicide time series overlaid with the values fitted by the statistical model, shows that the model fit the data well. Alternatively, formulating the association between legalization and the number of homicides as a change in slope fit the data nearly as well, but did not change the overall story. As a descriptive matter, homicides declined noticeably after the legalization of abortion, but the null hypothesis could not be rejected at conventional levels for either a change in level or a change in slope.

Insert Figure 3 about here

\section{$\underline{\text { Toddlers }}$}

Figure 4 shows the annual time series of the number of toddlers who died of homicide from 1960 through 1998. The number of homicides range from a low of about 125 to a high of nearly 500, with a clear upward trend over time. However, the average rate of increase seems to slow starting around 1973, suggesting a reduction in the slope. We estimated a transfer function model to reflect this reduction. Findings are reported in the bottom panel of Table 2. ${ }^{\text {b }}$

Insert Figure 4 about here

${ }^{\mathrm{b}}$ There was no need to include an intervention for the introduction of the SIDS classification in 1979 because it did not apply to toddlers, but we initially included the possible effects of the 1968 introduction of the "underdetermined" classification. Although, as expected from Figure 4, we found a substantial negative association between legalization and the number of homicides, the coefficient for the 1968 measurement artifact had a counterintuitive positive association coupled with a p-value of .32. It was also somewhat correlated with the variable for abortion legalization, which reduced statistical power. Consequently, we dropped the "undetermined" intervention. 
There is a reduction of about 8.5 homicides per year in the rate of growth starting in 1975, two years after the legalization of abortion $(\mathrm{p}=.04)$. The change in the rate of growth implies that the reductions accumulate each year so that by 1980, for example, there would be about 40 fewer homicides than would be expected if the rate of growth did not slow. Figure 5 provides a visual representation of the change.

Insert Figure 5 about here

Figure 6 shows that the model fit the data well. Nonetheless, we investigated whether the change in homicides would be represented better by using different time periods (e.g., lags) following the legalization of abortion (e.g., whether an immediate effect could be observed, whether the effect was stronger years later). The overall conclusions did not change when we reformulated the transfer function to allow for different lags. For lags of up to 3 years, the fit of the model was quite good. The associations between the legalization of abortion and the homicides of young children remained negative, although smaller, as one would expect. We also experimented with a transfer function to capture a change in level instead of change in slope. That model did not fit as well and no compelling associations with the legalization of abortion materialized. Thus, the effect for toddlers seemed to be most apparent in 1975 and to be best represented as a change in slope.

Insert Figure 6 about here 


\section{Discussion}

The U.S. Supreme Court decision in Roe v. Wade is associated with a gradual reduction in the number of homicides of children who are one to four years old. The effect is seen in 1975, two years after the legalization of abortion nationwide, a time generally consistent with when abortion services were likely to have become more widely available. There are three, and perhaps more, mechanisms that might explain the association. First, with fewer unwanted children, there are fewer stresses on parents who might be inclined to take out their frustrations and hostilities on their children. This would be true for children of all ages in the home. In a related vein, familial resources (e.g., child care, finances) would be divided among a fewer number of children rather than stretched to accommodate a newborn. Third, abortion reduces, theoretically at least, unwanted children who themselves might have become targets if not immediately then over time. Over time, for example, the best intentions to make the best of a bad situation might be worn down so that at an age of a year or older more serious abuse begins. In addition, as the child grows older and exhibits more independent and sometimes difficult behavior, a hostile parent may be provided with the rationale for abuse under the guise of discipline.

The story for infants is less clear. We find evidence for a reduction in homicide at the expected time, but Type I error (false positives) can not be ruled out. In other words, although the results are in the predicted direction, the legalization of abortion appears to have had a limited, one-time, and not statistically significant association with the homicide of children under the age of one year. Why might that be? One possibility is that because the infant series we analyzed is more variable, it is harder to separate a genuine effect from "noise.” Another possibility is because of the physiological vulnerability of newborns, some of the homicides do 
not reflect sustained abuse (which one might postulate for unwanted children) but a momentary lapse in self control that can happen even with parents of wanted children. Abortion legalization would not have an impact on these types of homicides.

Previous research has documented a decline in abortion-related deaths of women following the legalization of abortion (Council on Scientific Affairs, 1992). And the decrease continued for years afterwards. Deaths from legal abortion dropped from 3.3 deaths to 0.4 death per 100,000 procedures between 1973 and 1985, perhaps reflecting improved physician education and skill, improvements in medical technology, and the earlier termination of pregnancy (Council on Scientific Affairs, 1992). Whereas the mechanism linking the legalization of abortion with fewer abortion-related fatalities among women may be fairly straightforward, the mechanism is less clear for the subsequent reduction in homicide among young children.

\section{Study Strengths and Limitations}

We included the deaths of all young children that were classified as homicides in U.S. vital statistics mortality data during the years 1960 through 1998 . Working with all of the infant and toddler homicides in that period, we are able to examine the potential association between the federal legalization of abortion and child homicide. The 38 years of data, consisting of 12 years before and 26 years after the legalization of abortion, provides a reasonable time span in which to examine any association between legalized abortion and child homicide.

We relied on a straightforward design that used the federal decision to legalize abortion as the intervention. Some might want to conduct state-level analyses that take into account the fact that five states—Washington, New York, Alaska, Hawaii, and California—legalized abortion prior to the federal decision. As noted previously, circumstances under which abortion 
was allowed in those states remained quite limited; it was only with the U.S. Supreme Court decision that legalized abortion became more widely available. In addition, geographic mobility limits the usefulness of state-level comparisons. Some pregnant women travel to other states to obtain an abortion. This might have been the case especially when some states had legalized abortion before the Roe v. Wade decision--pregnant women who were particularly desperate but who wanted a legal abortion or those of greater means might have traveled to one of the five states where abortion was legal. Abortion data contain information about state of residence--the estimated proportion of abortions provided to nonresidents in 1994 ranges from about 50\% in the District of Columbia to about 2\% in New Jersey (Koonin, Smith, Ramick, Strauss, \& Hopkins, 1997). However, even recent residency data are limited; for example, in 1994, 10 states did not collect information on residency (Koonin, et al., 1997). Moreover, geographic mobility may be a problem in another way. Although it likely would be a small problem for the infants and a somewhat larger problem for the 1- to 4-year olds, $8.6 \%$ of the U.S. population moved to another state from 1970 to 1975 (U.S. Bureau of the Census, 1976). Using national data helped avoid the geographic mobility complication inherent in state-level analyses.

Other events might account for the findings, and we investigated the possibility that two changes in the data classification scheme might have influenced the findings. The 1968 introduction of the category of "undetermined” into the classification scheme was associated, among children under one year of age, with an abrupt drop in the number of deaths that were classified as homicides. No such drop was observed for one- to four-year olds. For both groups, the legalization of abortion was associated with the reduction of homicide above and beyond the change in the classification scheme (although for infants the weight of the evidence against a false positive does not meet conventional levels). The introduction of SIDS into the 
classification scheme was not associated with a change in the designation of homicides of infants, the only age group that would be affected by such a change.

The investigation was limited to an empirical investigation of the question. Whether the observed association between legalized abortion and the reduction of homicide among toddlers was due to improved timing of births, a decrease in unwanted births, reduced family size, or some other mechanism is beyond the reach of these data. Moreover, the ethical and moral implications of the association between the legalization of abortion and child homicide are beyond the scope of this paper.

\section{$\underline{\text { Conclusions }}$}

The 1973 legalization of abortion in the U.S. was associated with a statistically significant reduction in the number of 1- to 4-year old homicide victims in subsequent years. The homicides of infants were decreased but the change was not statistically significant. Events coinciding with the Roe v. Wade decision might have had an impact on infant and toddler homicide mortality but we are hard-pressed to generate alternative explanations. For example, perhaps the 1972 introduction of WIC (Women, Infants, and Children), the federally-funded nutrition program for low income women and nursing mothers, had an effect on child health but it is difficult to fathom the basis for an association between improved nutrition and a decrease in the homicide of toddlers. We do not, however, claim that we have definitely demonstrated a causal relationship between the legalization of abortion and the subsequent reduction in the homicide of 1- to 4-year olds.

Therapeutic abortion appears to play a unique role in women’s reproductive choices. Despite sex education in schools, widespread youth clinics, and free family planning services, more than 30,000 legal abortions are performed each year in Sweden (Larsson, Aneblom, 
Odlind, \& Tyden, 2002). One can only speculate what would have happened if these women were unable to obtain an abortion. Longitudinal European research concludes that children born in such circumstances are more psychosocially disadvantaged than their peers (Forssman \& Thuwe, 1966; David, 1992). Such information is relevant given that multiple barriers to abortion services exist in the U.S. including distance, gestational limits, cost, and harassment (Henshaw, 1991, 1995, 1998).

Given that policies are implemented in a social milieu consisting of many unmeasured and perhaps unmeasurable characteristics, it is difficult to determine the effects of any single policy. Moreover, it is difficult to assess the unintended and unanticipated consequences of national policy decades after the fact. Nonetheless, given the health implications of national policy, such as in Roe $v$. Wade, it is critical that the effects of such policy be examined and estimated. Such difficulty underscores the need for further study of the intended and unintended effects of national health policy. 


\section{References}

Alan Guttmacher Institute. (2000). Induced abortion (US), 2000. Available at: http://www.agi-usa.org/pubs/fb_induced_abortion.html. Accessed June 17, 2001.

Bauman, K. E., \& Anderson, A. E. (1980). Legal abortions and trends in fetal and infant mortality rates in the United States. Amerian Journal of Obstetrics and Gynecology, 136, 194-202.

Berk, R.A., Sorenson, S.B., Wiebe, D.J., \& Upchurch, D.M. (under review). Youth homicide and the legalization of abortion.

Blum R.W., \& Resnick, M.D. (1982). Adolescent sexual decision-making: Contraception, pregnancy, abortion, motherhood. Pediatric Annals, 11, 797-805.

Box, G. E. P., Jenkins, G. M, \& Reinsel, G. C. (1994) Time Series Analysis (3 ${ }^{\text {rd }}$ ed.). Prentice Hall.

Bracken, M.C., Klerman, L.V., \& Bracken, M. (1978). Abortion, adoption, or motherhood: An empirical study of decision-making during pregnancy. American Journal of Obstetrics and Gynecology, 130, 251-262.

Bracken, M.B. Hachamovitch, M., \& Grossman, G. (1974). The decision to abort and psychological sequelae. Journal of Nervous and Mental Disorder, 158, 154-162.

Christoffel, K.K. (1984). Homicide in childhood: a public health problem in need of attention. American Journal of Public Health, 74, 68-70.

Council on Scientific Affairs, American Medical Association. (1992). Induced termination of pregnancy before and after Roe v Wade. Trends in the mortality and morbidity of women. Journal of the American Medical Association, 268, 3231-3239. 
David, H.P. (1992). Born unwanted: Long-term developmental effects of denied abortion. Journal of Social Issues, 48, 163-181.

Donohue, J. J. \& Levitt, S. D. (2001). The impact of legalized abortion on crime. Quarterly Journal of Economics, CXVI, 379-420.

Faria, G., Barrett, E., \& Goodman, L.M. (1985). Women and abortion: Attitudes, social networks, and decision-making. Social Work in Health Care, 11, 85-99.

Finken, L.L. \& Jacobs, J.E., (1996). Consultant choice across decision contexts: Are abortion decisions different? Journal of Adolescent Research, 11, 235-260.

Ford, C.V., Castelnuovo-Tedesco, P., \& Long, K.D. (1972). Women who seek therapeutic abortion: A comparison with women who complete their pregnancies. American Journal of Psychiatry, 129, 546-552.

Forssman, H., \& Thuwe, I. (1966). One hundred and twenty children born after application for therapeutic abortion refused. Acta Psychiatric Scandinavica, 42, 71-88.

Fox, J. A., \& Zawitz, M. W. (2000). Homicide Trends in the United States: 1998 Update. NCJ 179767. Rockville, MD: U.S. Dept. of Justice, Office of Justice Programs, Bureau of Justice Statistics.

Friedlander, M.L., Kaul, T.J., \& Stimel, C.A. (1984). Abortion: Predicting the complexity of the decision-making process. Women \& Health, 9, 43-54.

Friedman, C.M., Greenspan, R., \& Mittleman, R. (1974). The decision-making process and the outcome of therapeutic abortion. American Journal of Psychiatry, 131, 1332-1337. Henshaw, S.K. (1991). The accessibility of abortion services in the United States. Family Planning Perspectives, 23, 246-253. 
Henshaw, S.K. (1995). Factors hindering access to abortion services. Family Planning Perspectives, 27, 54-59, 87.

Henshaw, S.K. (1998). Barriers to access to abortion services. In L.J. Beckman \& S.M. Harvey (Eds.), The new civil war: The psychology, culture, and politics of abortion (pp. 6180). Washington, D.C.: American Psychological Association.

International Classification of Diseases. Manual of the international statistical classification of diseases, injuries, and causes of death. $7^{\text {th }}$ rev. Geneva, Switzerland: World Health Organization; 1955.

International Classification of Diseases. Manual of the international statistical classification of diseases, injuries, and causes of death. $8^{\text {th }}$ rev. Geneva, Switzerland: World Health Organization; 1969.

International Classification of Diseases. Manual of the international statistical classification of diseases, injuries, and causes of death. $9^{\text {th }}$ rev. Geneva, Switzerland: World Health Organization; 1977.

Jason, J., Gilliland, J. C., \& Tyler, C. W. (1983). Homicide as a cause of pediatric morality in the United States. Pediatrics, 72, 191-197.

Johnstone, F.D., Brettle, R.P., MacCallum, L.R., Mok, J.,Peutherer, J.F., \& Burns, S. (1990). Women's knowledge of their HIV antibody state: Its effect on their decision whether to continue the pregnancy. British Medical Journal, 300, 23-24.

Joyce, T. (2001). Did legalized abortion lower crime? NBER Working Paper No. W8319. Available at: http://papers.nber.org/papers/W8319. Accessed June 17, 2001. 
Koonin, L.M., Smith, J. C., Ramick, M., Strauss, L. T., \& Hopkins, F. W. (1997).

Abortion surveillance--United States, 1993 and 1994. Morbidity and Mortality Weekly Reports, 46(SS-4), 37-98.

Koonin, L.M., Strauss, L.T., Chrisman, C.E., \& Parker, W.Y. (2000). Abortion surveillance - United States, 1997. Morbidity and Mortality Weekly Report, 49, SS11, 1-44.

Larsson, M., Aneblom, G., Odlind, F., \& Tyden, T. (2002). Reasons for pregnancy termination, contraceptive habits and contraceptive failure among Swedish women requesting an early pregnancy termination. Acta Obstetics Gynecology Scandinavia, 81, 6471.

Lester, D. (1992). Roe v Wade was followed by a decrease in neonatal homicide. Journal of the American Medical Association, 167,3027-3028.

Lott, J. R., \& Whitley, J. (2001). Abortion and crime: Unwanted children and out-ofwedlock births. Yale Law School Working Paper \#254. Available at: http://papers.ssrm.com/paper.taf?abstract_id=270126. Accessed June 17, 2001.

Luscutoff, S.A., \& Elms, A.C. (1975). Advice in the abortion decision. Journal of Counseling Psychology, 22, 140-146.

McClain, P. W., Sacks, J. J., Froehlke, R. G,, \& Ewigman, B. G. (1993). Estimates of fatal child abuse and neglect, United States, 1979 through 1988. Pediatrics, 91, 338-343.

Merz, J. F., Jackson, C. A., \& Klerman, J. A. (1995). A review of abortion policy Legality, Medicaid funding, and parental involvement, 1967-1994. Women’s Rights Law Reporter, 1, 17.

Murphy, S. L. (2000). Final Data for 1998. National Vital Statistics Reports; vol 48 no. 11. Hyattsville, MD: National Center for Health Statistics. 
National Center for Health Statistics. Vital Statistics of the United States, 1960-1998 (individual years), Vol. 2, Mortality, Part B. Department of Health and Human Services. Public Health Service. Washington, DC: U.S. Government Printing Office.

Ortiz, C.G., \& Vazquez Nuttal, E. (1987). Adolescent pregnancy: Effects of family support, education, and religion on the decision to carry or terminate among Puerto Rican teenagers. Adolescence, 22, 897-917.

Overpeck, M. D., Brenner, R. A., Trumble, A. C., Trifiletti, L. B., \& Berendes, H. W. (1998). Risk factors for infant homicide in the United States. New England Journal of Medicine, 339, 1211-1216.

Quick, J. D. (1978). Liberalized abortion in Oregon: effects on fertility, prematurity, fetal death, and infant death. American Journal of Public Health, 68, 1003-1008.

Robertson, L. S. (1981). Abortion and infant mortality before and after the 1973 US Supreme Court decision on abortion. Journal of Biosocial Science, 13, 275-280.

Rosen, R.H., \& Martindale, L.J. (1978 ). Sex role perceptions and the abortion decision. Journal of Sex Research, 14, 231-245.

Russo, N.F., \& Denious, J.E. (1998). Why is abortion such a controversial issue in the United States? In L.J. Beckman \& S.M. Harvey (Eds.), The new civil war: The psychology, culture, and politics of abortion (pp. 25-60). Washington, D.C.: American Psychological Association.

Russo, N.F., Horn, J.D., \& Schwartz, R. (1992). U.S. abortion in context: Selected characteristics and motivations of women seeking abortions. Journal of Social Issues, 48, 183-202. 
Schechtman, K.B., Gray, D.L., Baty, J.D., \& Rothman, S.M. (2002). Decision-making for termination of pregnancies with fetal anomalies: Analysis of 53,000 pregnancies. Obstetrics and Gynecology, 99, 216-222.

Smetana, J.G. (1982). Reasoning in the personal and moral deomains: Adolescent and youg adults women’s decision-making regarding abortion. Journal of Applied Developmental Psychology, 2, 211-226.

Sorenson, S. B., Shen, H., \& Kraus, J. F. (1997a). Undetermined manner of death: A comparison with unintentional injury, suicide, and homicide death. Evaluation Review, 21, 43-57.

Sorenson, S. B., Shen, H., \& Kraus, J. F. (1997b). Coroner-reviewed infant and toddler deaths: Many “undetermineds” resemble homicides. Evaluation Review, 21, 58-76.

Stevans, L.K., Register, C.A., \& Sessions, D.N. (1992). The abortion ecision: A qualitative choice approach. Social Indicators Research, 27, 327-344.

Torres, A., \& Forrest, J.D. (1988). Why do women have abortions? Family Planning Perspectives, 20, 169-176.

U.S. Bureau of the Census. (1976). Statistical Abstract of the United States: 1976. (97th edition.) Washington, D.C.: U.S. Bureau of the Census. (Table 33. Mobility Status of the Population, By Geographic Regions: 1970 to 1975.)

Ventura S.J., Mosher, W.D., Curtin, S.C., Abma, J.C., \& Henshaw, S. (2000). Trends in pregnancies and pregnancy rates by outcome: Estimates for the United States, 1976-96. Vtial Health Statistics, Series 21, No. 56, 1-47.

Wilcox, B.L., Robbennolt, J.K., \& O’Keeffe, J.E. (1998). Federal abortion policy and politics: 1973 to 1996. In L.J. Beckman \& S.M. Harvey (Eds.), The new civil war: The 
psychology, culture, and politics of abortion (pp. 3-24). Washington, D.C.: American Psychological Association.

Winpisinger, K. A., Hopkins, R. S., Indian, R. W., \& Hostetler, J. R. (1991). Risk factors for childhood homicide in Ohio: A birth certificate-based case-control study. American Journal of Public Health, 81, 1052-1054. 
Table 1. Number of homicide, unintentional injury, undetermined and SIDS deaths of young children, U.S., 1960-1998

\begin{tabular}{|c|c|c|c|c|c|c|c|}
\hline & \multicolumn{2}{|c|}{$\underline{\text { Homicide }}$} & \multicolumn{2}{|c|}{ Unintentional injury } & \multicolumn{2}{|c|}{ Undetermined } & \multirow{2}{*}{$\begin{array}{l}\underline{\text { SIDS }} \\
<1 \text { year }\end{array}$} \\
\hline & $<1$ year & 1-4 years & $<1$ year & 1-4 years & $<1$ year & 1-4 years & \\
\hline 1960 & 199 & 116 & 3831 & 5119 & . & . & . \\
\hline 1961 & 192 & 169 & 3581 & 5041 & . & . & . \\
\hline 1962 & 205 & 145 & 3653 & 5053 & . & . & . \\
\hline 1963 & 195 & 184 & 3514 & 5174 & . & . & . \\
\hline 1964 & 219 & 200 & 3406 & 5184 & . & . & . \\
\hline 1965 & 213 & 189 & 3316 & 5270 & . & . & . \\
\hline 1966 & 211 & 189 & 3096 & 5411 & . & . & . \\
\hline 1967 & 226 & 172 & 2751 & 5074 & . & . & . \\
\hline 1968 & 163 & 213 & 2520 & 4743 & 99 & 155 & . \\
\hline 1969 & 151 & 238 & 2425 & 4548 & 127 & 179 & . \\
\hline 1970 & 150 & 258 & 2570 & 4733 & 126 & 175 & . \\
\hline 1971 & 187 & 295 & 2549 & 4718 & 112 & 177 & . \\
\hline 1972 & 172 & 246 & 1784 & 4358 & 94 & 174 & . \\
\hline 1973 & 160 & 342 & 1972 & 4836 & 90 & 148 & . \\
\hline 1974 & 166 & 296 & 1727 & 4347 & 108 & 169 & . \\
\hline 1975 & 178 & 317 & 1609 & 4073 & 94 & 145 & . \\
\hline 1976 & 170 & 306 & 1526 & 3991 & 103 & 146 & . \\
\hline 1977 & 177 & 330 & 1455 & 3759 & 105 & 132 & . \\
\hline 1978 & 161 & 313 & 1507 & 3932 & 84 & 115 & 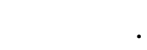 \\
\hline 1979 & 170 & 314 & 1080 & 3349 & 81 & 85 & 5279 \\
\hline 1980 & 210 & 319 & 1166 & 3313 & 68 & 98 & 5510 \\
\hline 1981 & 189 & 360 & 981 & 2649 & 77 & 77 & 5295 \\
\hline 1982 & 218 & 379 & 1024 & 3084 & 71 & 64 & 5278 \\
\hline 1983 & 193 & 320 & 956 & 3043 & 55 & 67 & 5305 \\
\hline 1984 & 237 & 341 & 838 & 2814 & 59 & 55 & 5874 \\
\hline 1985 & 200 & 348 & 890 & 2856 & 52 & 66 & 5315 \\
\hline 1986 & 278 & 382 & 909 & 2934 & 50 & 49 & 5278 \\
\hline 1987 & 273 & 334 & 950 & 2921 & 53 & 71 & 5230 \\
\hline 1988 & 315 & 381 & 936 & 2858 & 39 & 54 & 5476 \\
\hline 1989 & 335 & 393 & 996 & 2774 & 51 & 56 & 5634 \\
\hline 1990 & 332 & 377 & 930 & 2566 & 53 & 31 & 5417 \\
\hline 1991 & 380 & 428 & 961 & 2665 & 48 & 41 & 5349 \\
\hline 1992 & 326 & 429 & 819 & 2467 & 41 & 34 & 4891 \\
\hline 1993 & 344 & 464 & 898 & 2590 & 61 & 39 & 4669 \\
\hline 1994 & 313 & 473 & 889 & 2517 & 47 & 47 & 4073 \\
\hline 1995 & 311 & 452 & 787 & 2280 & 57 & 45 & 3397 \\
\hline 1996 & 332 & 420 & 804 & 2147 & 58 & 54 & 3050 \\
\hline 1997 & 317 & 375 & 765 & 2005 & 57 & 40 & 2991 \\
\hline 1998 & 322 & 399 & 754 & 1935 & 75 & 43 & 2822 \\
\hline
\end{tabular}

Data source: National Center for Health Statistics. Vital statistics of the United States for 19601998, vol II, mortality, part A. Washington: Public Health Service. Published annually. 
Table 2. Relationship between legalized abortion and the homicide of young children

$\underline{\text { Infants (less than } 1 \text { year old) }^{1}}$

$\begin{array}{lcc} & \underline{\mathrm{b}} & \underline{\mathrm{p}-\text { level }} \\ \text { Abortion legalization } & -26.73 & .383 \\ \text { Introduction of “undetermined” } & -72.47 & .025 \\ \text { Introduction of SIDS } & 8.73 & .602 \\ \text { AR } & -0.59 & .001 \\ \text { Constant } & 5.75 & -- \\ & & \\ \text { SE } & & -\end{array}$

Toddlers (1- to 4-years old $)^{2}$

b $\quad$ p-level

Abortion legalization

$-8.56 \quad .036$

MA

$-0.57 \quad .001$

Constant

12.80

29.25

SE

$29.25 \quad--$

1 Results of ARIMA $(1,1,0)$ model. AR denotes autoregressive parameter.

2 Results of ARIMA $(0,1,1)$ model. MA denotes moving average parameter. 



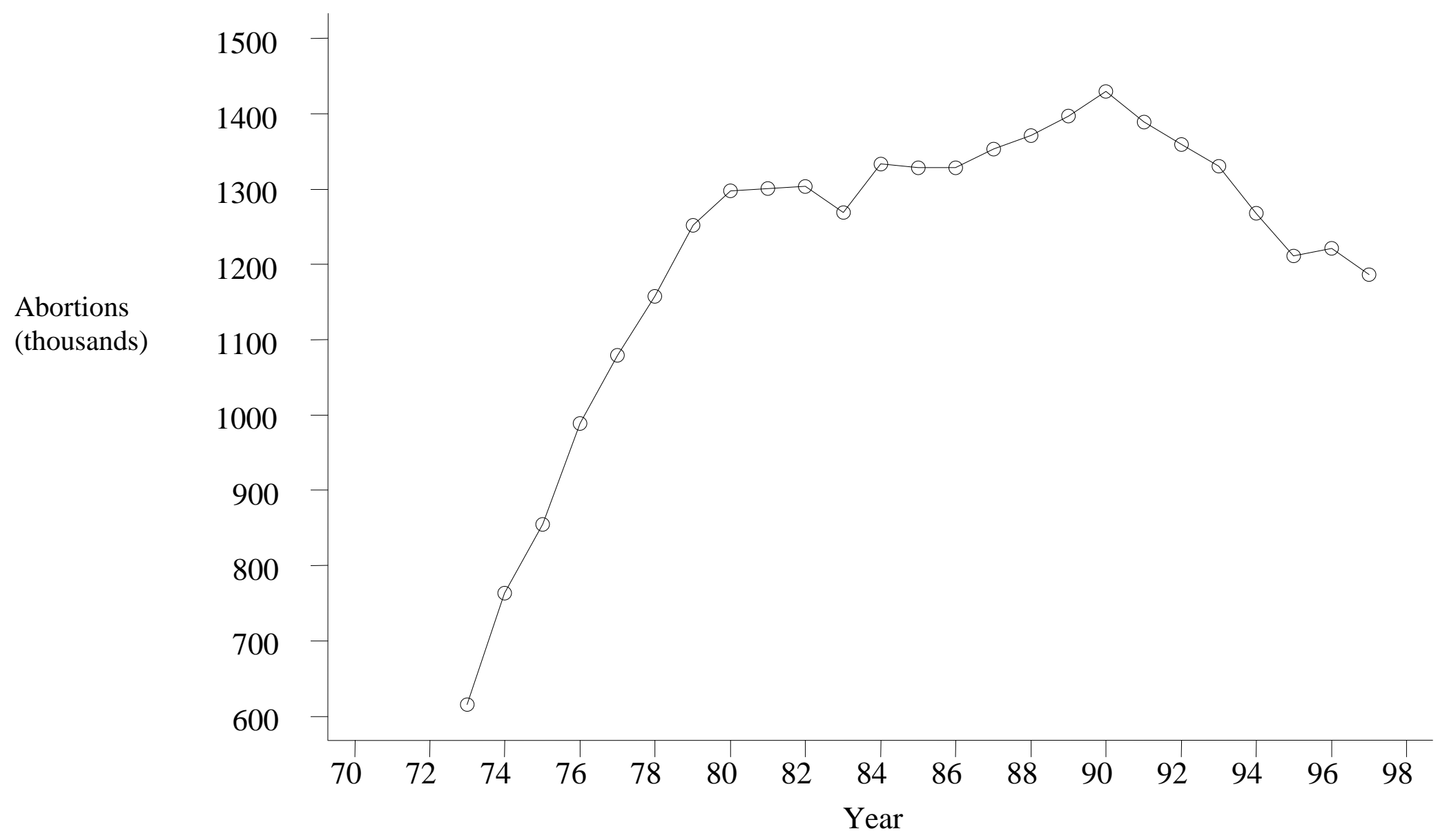

Figure 1. Number of legal abortions, U.S., 1973-1998

Data source: Abortion Surveillance for 1960-1998, Centers for Disease Control and Prevention, U.S. Department of Health and Human Services. Published annually. 


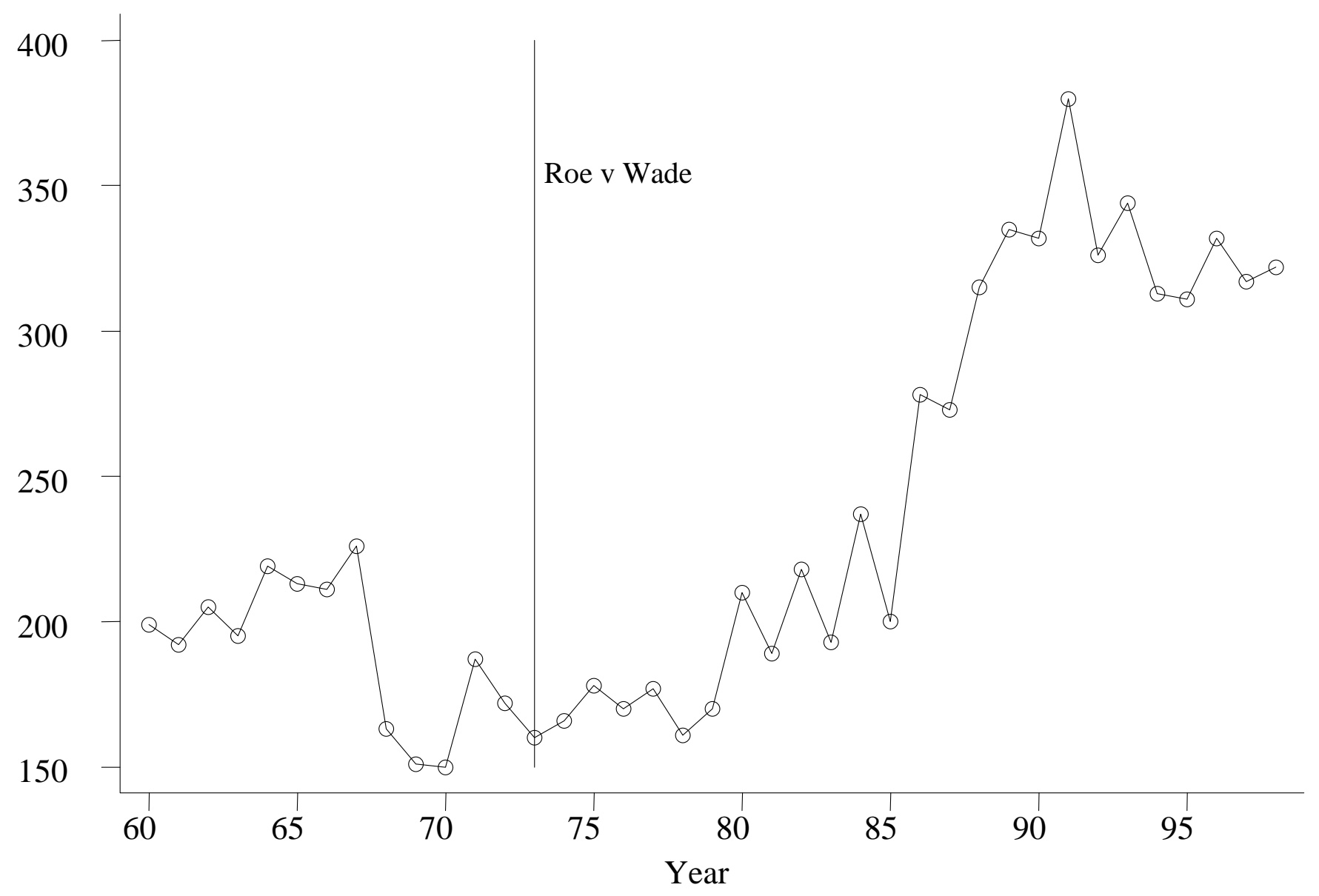

Figure 2. Number of homicides of children under one year of age, U.S., 1960-1998

Data source: National Center for Health Statistics. Vital statistics of the United States for 1960-1998, vol II, mortality, part A. Washington: Public Health Service. Published annually. 


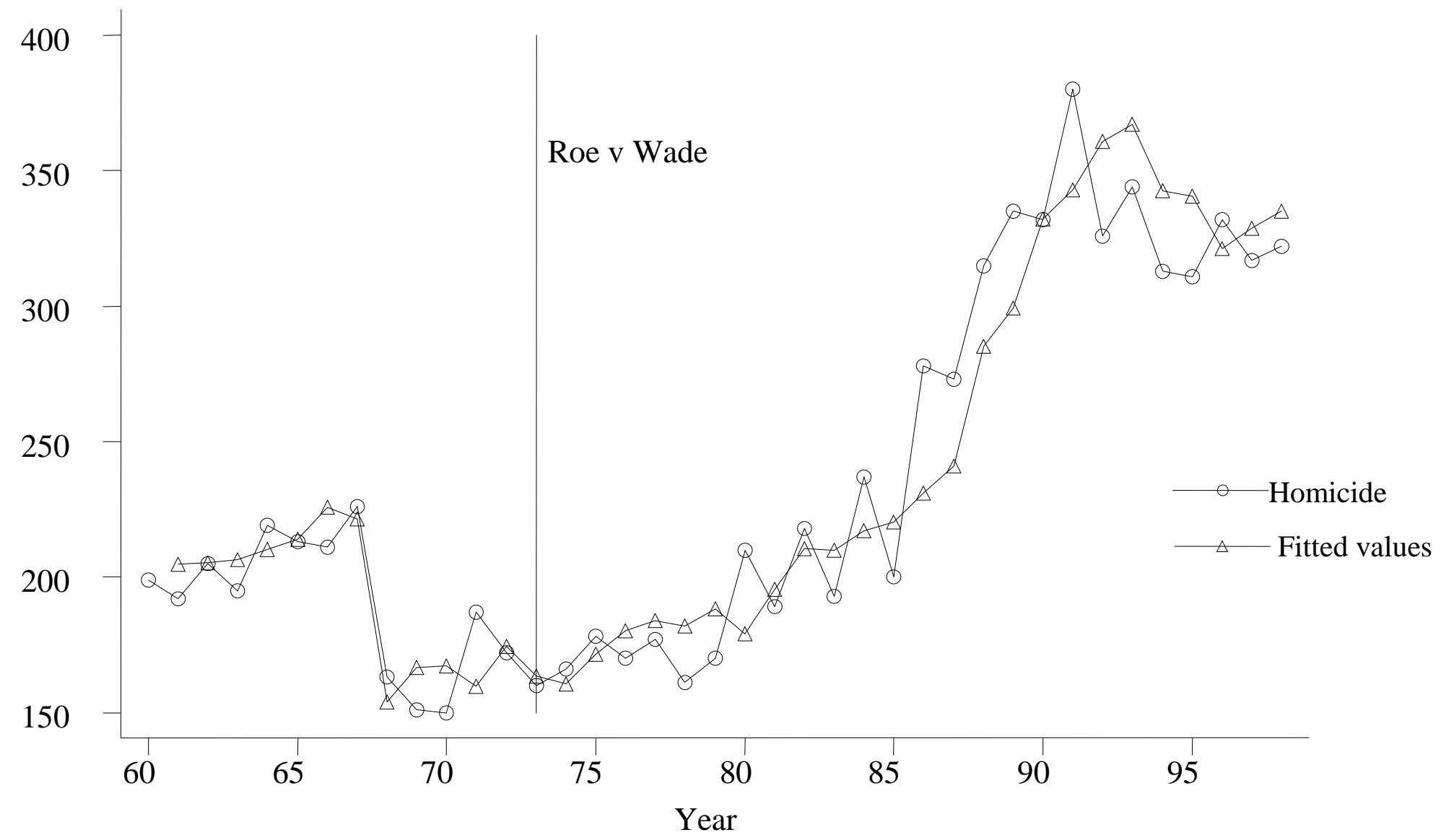

Figure 3. Homicides of children less than one year old and fitted values 


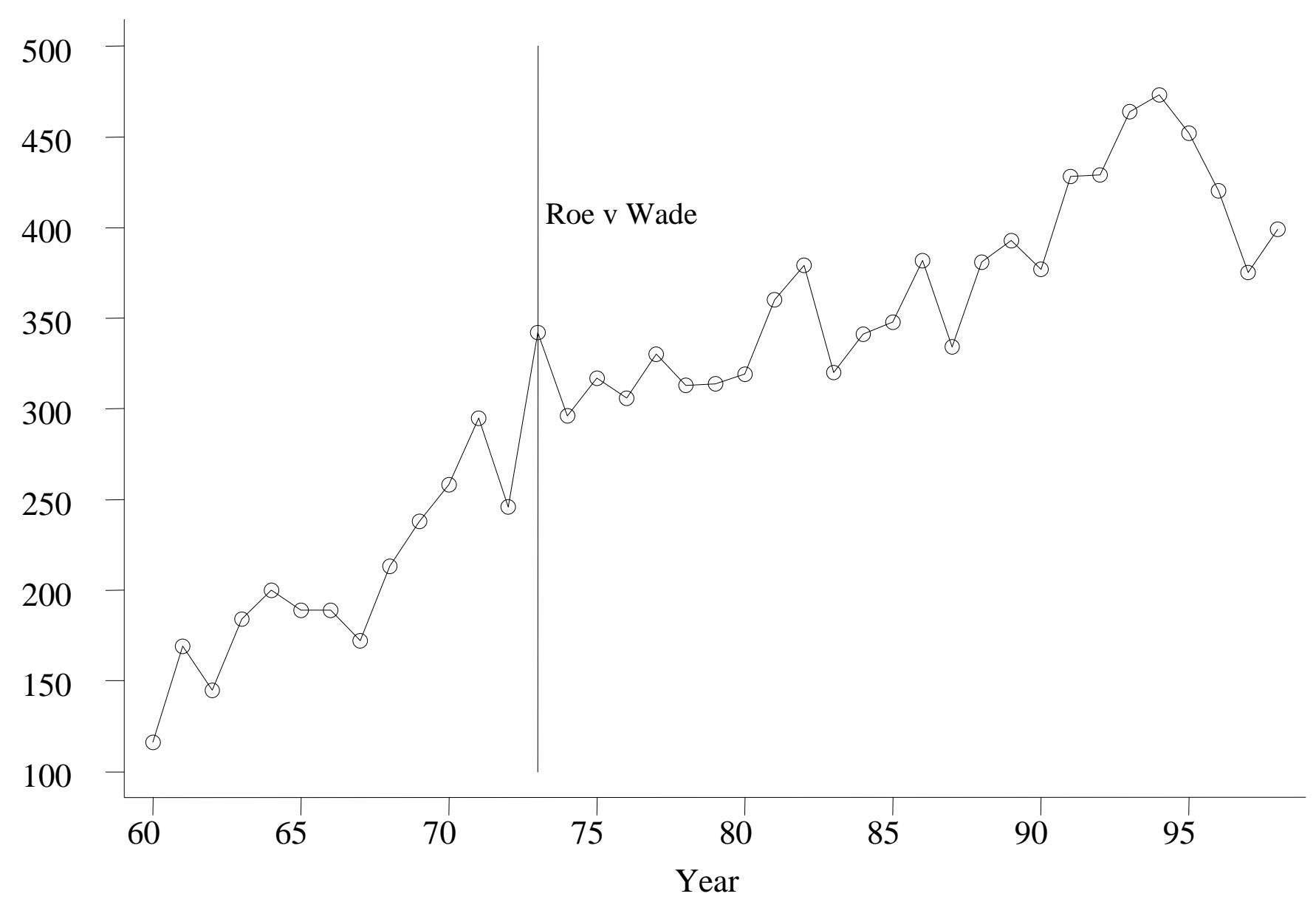

Figure 4. Number of homicides of one- to four-year olds, U.S., 1960-1998

Data source: National Center for Health Statistics. Vital statistics of the United States for 1960-1998, vol II, mortality, part A. Washington: Public Health Service. Published annually. 


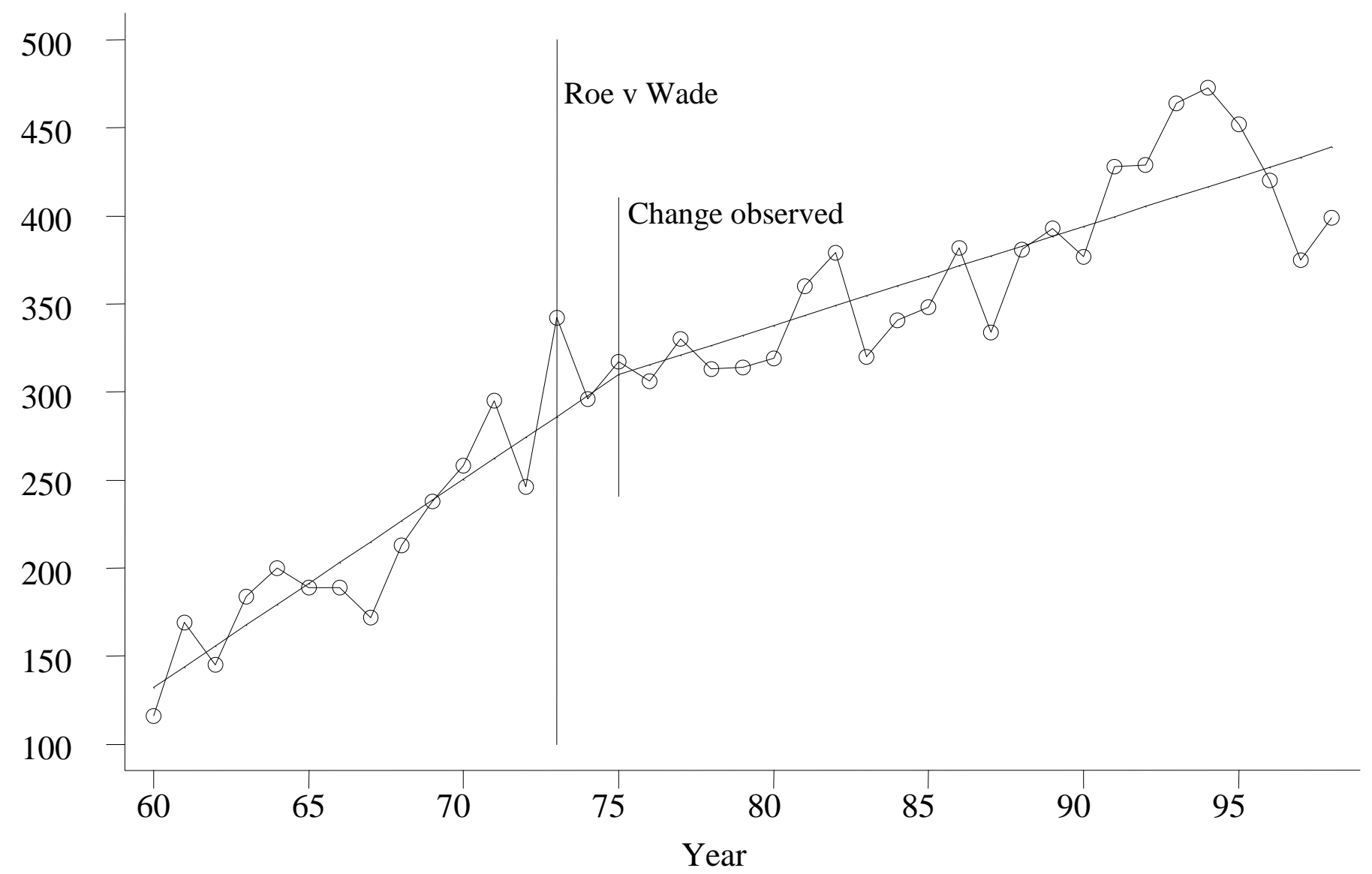

Figure 5. Homicides of one- to four-year olds, with slopes to show the rate of homicide before and after abortion legalization

Data source: National Center for Health Statistics. Vital statistics of the United States for 1960-1998, vol II, mortality, part A. Washington: Public Health Service. Published annually. 


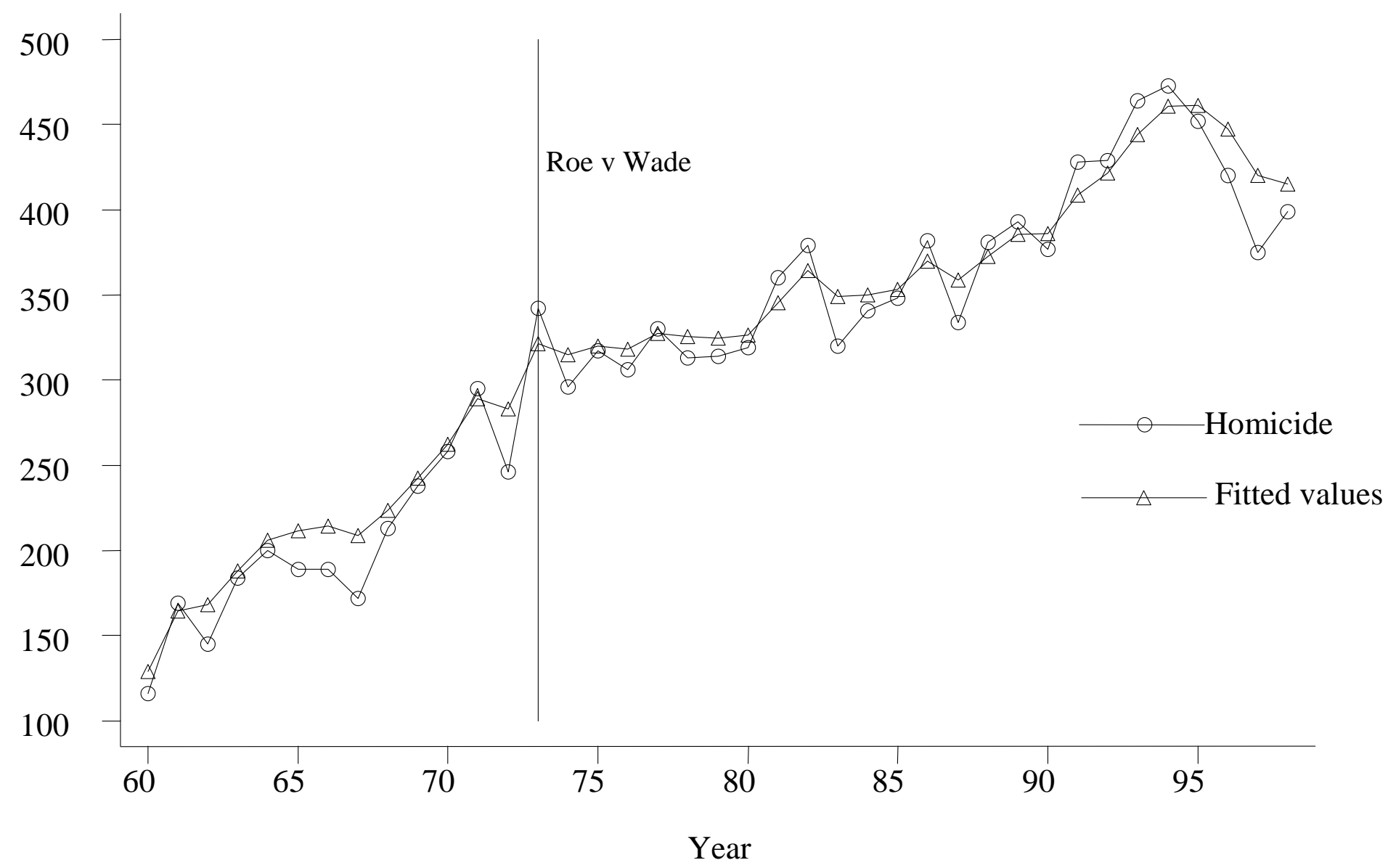

Figure 6. Homicides of children one- to four-years old and fitted values 


\section{Acknowledgments}

The project is funded, in part, by a grant from The California Wellness Foundation (TCWF). Created in 1992 as an independent, private foundation, TCWF's mission is to improve the health of the people of California by making grants for health promotion, wellness education and disease prevention programs. The project is also funded, in part, by the Public Health Foundation through a grant from the California Endowment. 